\title{
PENGARUH TERAPI REMINISCENCE TERHADAP HARAPAN HIDUP LANSIA
}

\author{
Ana Ikhsan Hidayatulloh', Eriska Valency ${ }^{2}$, Ai Rahmawati ${ }^{3}$ \\ Universitas Bhakti Kencana Tasikmlaya ${ }^{1,2,3}$ \\ ana.ikhsan@bku.ac.id
}

\begin{abstract}
ABSTRAK
Penelitian ini yaitu sesuai dengan hasil survei pendahuluan yang dilakukan oleh penulis pada tanggal 5 juli 2021 terhadap 30 lansia di Panti Werdha Welas Asih Singaparna Kabupaten Tasikmalaya menyebutkan bahwa harapan hidup lansia di Panti Werdha Welas Asih Singaparna Kabupaten Tasikmalaya ada pada kategori harapan hidup rendah sebelum diberikan intervensi terapi reminiscence yaitu sebanyak 14 orang (47\%) dan setelah diberikan intervensi terapi reminiscence ada pada kategori harapan hidup sedang yaitu sebanyak 26 orang $(87 \%)$ yang menunjukan adanya peningkatan. Penelitian ini bertujuan untuk mengetahui harapan hidup lansia di Panti Werdha Welas Asih Singaparna Kabupaten Tasikmalaya sebelum dan setelah diberikan intervensi terapi reminiscence. Metode yang digunakan adalah Quasi Experimental dengan jumlah populasi sebanyak 30 lansia di Panti Werdha Welas Asih Singaparna Kabupaten Tasikmalaya. Data hasil penelitian dianalisa menggunakan uiji Paired T. Hasil penelitian menunjukan bahwa hasil uji statistic didapatkan sig (2-tailed) sebesar 0,000 (a < 0,05). Hal ini menunjukan bahwa Ho ditolak yang artinya ada pengaruh yang signifikan antara terapi reminiscence terhadap harapan hidup lansia di Panti Werdha Welas Asih Singaparna Kabupaten Tasikmalaya, dan disarankan untuk lansia yang memiliki harapan hidup rendah, diharapkan lebih berusaha untuk meningkatkan harapan hidupnya. Pembahasan terkait pengaruh terapi reminiscence terhadap harapan hidup lansia dijadikan tambahan kepustakaan di bidang ilmu keperawatan, agar dapat memperluas pengetahuan mahasiswa dalam mempelajarinya.
\end{abstract}

\section{Kata kunci : Harapan Hidup, Lansia , Terapi Reminiscence}

\section{ABSTRACT}

The background of this research, which is in accordance with the results of a preliminary survey conducted by the author on July 5, 2021, on 30 elderly people at the Welas Asih Singaparna Nursing Home, Tasikmalaya Regency, stated that the life expectancy of the elderly in the Welas Asih Singaparna Nursing Home in Tasikmalaya Regency was in the low life expectancy category before given reminiscence therapy intervention as many as 14 people (47\%) and after being given reminiscence therapy intervention there was a moderate life expectancy category as many as 26 people (87\%) which showed an increase. This study aims to determine the life expectancy of the elderly at the Welas Asih Nursing Home in Singaparna, Tasikmalaya Regency before and after being given reminiscence therapy interventions. The method used is Quasi Experimental with a population of 30 elderly people at the Singaparna Werdha Welfare Home, Tasikmalaya Regency. The research data were analyzed using the Paired T test. The results showed that the statistical test results obtained sig (2-tailed) of 0.000 ( $a$ < 
0.05). This shows that Ho is rejected, which means that there is a significant effect between reminiscence therapy on the life expectancy of the elderly at Panti Welas Asih Singaparna, Tasikmalaya Regency, and it is recommended that the elderly who have low life expectancy, are expected to make more efforts to increase their life expectancy. Discussions related to the effect of reminiscence therapy on the life expectancy of the elderly are used as additional literature in the field of nursing science, in order to expand students' knowledge in studying it.

\section{Keywords : Remniniscene Therapy, Life Expectancy, Elderly}

\section{PENDAHULUAN}

Penuaan merupakan suatu proses alamiah dimana hal tersebut berarti seseorang telah melalui tiga tahap kehidupannya. Tahapan tersebut diantaranya anak-anak, dewasa, dan tua. Berdasarkan hal itu menua terjadi hilangnya secara perlahan kemampuan yang tidak bisa banyak dilakukan setelah melewati tiga tahapan tersebut dan adanya perubahan baik fisik, mental, social, dan spiritual yang akan mempengaruhi hidup pada lansia diseluruh dunia. (Muhith, A. Sitoyo, 2016)

Harapan hidup (life ecpectancy) merupakan salah satu indikator yang dapat memotivasi dalam mendorong harapan pada lansia. Hal ini bertujuan untuk meningkatkan persepsi lansia terhadap kemampuannya sehingga dapat terkontrol. (Pastiwi, F., Nurfianti \& Hastuti, 2017)

Terapi yang dapat diberikan pada lansia guna meningkatkan harapan hidup tergolong cukup banyak. Diantaranya ada Terapi Tertawa, Terapi Warna (chromatherapy), Terapi Okupasi lansia, dan Terapi Reminiscence. Masing masing dari terapi tersebut memiliki keunggulan dan kekurangan dalam mengatasi masalah lansia. (Hermawan, 2015).

Refleksi terapi reminiscence ini tergolong kedalam terapi komplementer dimana tidak menggunakan obat obat alamiah tetapi efektif dapat diberikan kepada lansia guna mengatasi masalah yang berhubungan dengan psikologis lansia (Pramita, 2010).

Terapi reminiscence ini memiliki keunggulan menyalurkan perasaan dan emosi yang positif pada lansia. Metode ini menggunakan proses mengenang dan mengingat peristiwa masa lalu dengan prinsip yang mengandung unsur story telling (bercerita) dan berkomunikasi baik secara individu maupun kelompok yang hasilnya dapat meningkatkan kesejahteraan psikologis. (Lestari dan Nugraha 2017)

Kesejahteraan psikologis ini termasuk tujuan utama dalam terapi reminiscence. Metode terapi reminiscence dapat menjadi treatment psikologis yang menarik bagi para lanjut usia karena membuat mereka mempunyai ikatan masa lalu baik yang bersifat umum maupun khusus. (Poorneselvan \& Steefel, 2014) 
Menua merupakan suatu proses menghilangnya secara perlahan kemampuan jaringan untuk memperbaiki atau mengganti diri dan mempertahankan struktur dan fungsi normalnya sehingga tidak dapat bertahan dari jejas (termasuk infeksi) dan memperbaiki kerusakan yang di derita, Perubahan-perubahan yang terjadi meliputi perubahan fisik, perubahan mental dan psikologis, perubahan sosial, dan spiritual (Artinawati, 2014)

Harapan adalah suatu pemikiran yang dibentuk untuk mencapai tujuan atau keinginan, dengan menimbulkan energy sebagai motivasi yang menggerakkan individu melakukan langkah-langkah atau usaha-usaha yang telah dihasilkan.

Untuk pengukuran Harapan hidup seseorang yaitu menggunakan Hope Scale dimana Skor agency dan pathways sebagai dimensi utama harapan didapat dari perhitungan instrumen Hope Scale yang dikembangkan oleh Snyder (2000). Semakin tinggi nilai atau skor maka menunjukan individu memiliki harapan yang tinggi, begitupun sebaliknya jika skor hope scale rendah maka menunjukan individu memiliki harapan yang rendah pula.

Ada beberapa intervensi yang dapat diberikan kepada lansia mengenai harapan hidup yaitu Terapi Tertawa, Terapi Warna (chromatherapy) dan Terapi Okupasi lansia. Masing masing dari terapi tersebut memiliki keunggulan tersendiri namun ada salah satu terapi lain yang dapat diberikan kepada lansia guna meningkatkan harapan hidup lansia yaitu menggunakan metode terapi reminiscence. Dimana terapi ini memiliki keunggulan karena efektif dapat dilakukan kapan saja dan oleh siapapun tanpa terikat waktu.

Reminiscence adalah proses yang dikehendaki atau tidak dikehendaki untuk mengumpulkan kembali memori-memori seseorang pada masa lalu. Memori tersebut dapat merupakan suatu peristiwa yang mungkin tidak bisa dilupakan atau peristiwa yang sudah terlupakan yang dialami langsung oleh individu. Kemudian memori tersebut dapat sebagai kumpulan pengalaman pribadi atau "disharingkan" dengan orang lain (Gibson, 2011).

Reminiscence therapy dapat memfasilitasi penyesuaian lanjut usia terhadap proses penuaan dengan membantu lanjut usia memikirkan kembali dan memperjelas pengalaman- pengalaman sebelumnya, dan studi penelitian telah menunjukkan adanya peningkatan kesejahteraan psikologis setelah mendapat intervensi reminiscence therapy (Lestari and Nugraha , 2017). Berdasarkan latar belakang diatas maka perlu adanya penelitian bagaimana pengaruh terapi reminiscence terhadap harapan hidup lansia di panti werdha welas asih singaparna Kabupaten Tasikmalaya.

\section{METODE PENELITIAN}

Pada penelitian ini menggunakan Quasi Experimental desain dimana terdapat kelompok kontrol dan kelompok eksperimen 
tidak dipilih secara random. Peneliti menggunakan desain quasi experimental design yang menggunakan kelompok control karena dalam penelitian ini terdapat variabel-varibel dari luar yang tidak dapat dikontrol oleh peneliti (Nurussalam, 2015).
Populasi dalam penelitian ini adalah lansia yang berada di Panti Werdha Welas Asih Kecamatan Singaparna Tasikmalaya Jawa Barat yang berjumlah 30 orang dengan batas usia 60-74 tahun. Jumlah sampel dalam penelitian ini adalah sebanyak 30 Orang.

\section{HASIL PENELITIAN}

\section{Tabel 1}

Gambaran harapan hidup lansia sebelum diberikan intervensi

\begin{tabular}{lcc}
\hline Kategori & F & \% \\
\hline Rendah & 14 & $47 \%$ \\
Sedang & 12 & $40 \%$ \\
Tinggi & 4 & $13 \%$ \\
Total & $\mathbf{3 0}$ & $\mathbf{1 0 0 \%}$ \\
\hline
\end{tabular}

Berdasarkan tabel diatas sebagian besar ada pada kategori harapan hidup rendah yaitu $14(47 \%)$.

Tabel 2

Gambaran harapan hidup lansia setelah diberikan intervensi

\begin{tabular}{lcc}
\hline Kategori & F & \% \\
\hline Rendah & 2 & $7 \%$ \\
Sedang & 26 & $87 \%$ \\
Tinggi & 2 & $7 \%$ \\
Total & $\mathbf{3 0}$ & $\mathbf{1 0 0 \%}$ \\
\hline
\end{tabular}

Berdasarkan tabel diatas sebagian besar ada pada kategori harapan hidup sedang yaitu $26(87 \%)$.

Tabel 3

Hasil Uji Paired sampel T-Test

\begin{tabular}{|c|c|c|c|c|c|c|c|c|}
\hline \multicolumn{6}{|c|}{ Paired Differences } & \multirow{3}{*}{$\mathrm{t}$} & \multirow{3}{*}{ df } & \multirow{3}{*}{$\begin{array}{l}\text { Sige (2- } \\
\text { tailed) }\end{array}$} \\
\hline & \multirow[t]{2}{*}{ Mean } & \multirow{2}{*}{$\begin{array}{c}\text { Std. } \\
\text { Deviation }\end{array}$} & \multirow{2}{*}{$\begin{array}{l}\text { Std. Error } \\
\text { Mesn }\end{array}$} & \multicolumn{2}{|c|}{$\begin{array}{l}95 \% \text { Coufidence Interval of the } \\
\text { Differense }\end{array}$} & & & \\
\hline & & & & Lower & Upper & & & \\
\hline $\begin{array}{l}\text { Pre-Test Poost - } \\
\text { Test }\end{array}$ & -8.633 & 6.531 & 1.192 & -11.072 & -6.195 & -7.250 & 29 & .000 \\
\hline
\end{tabular}


Berdasarkan hasil uji paired sampel T-Test diketahui hasil signifikan/sig.(2-tailed) sebesar 0.000 dasar pengambilan keputusan pada uji paired sample test yaitu $<0.05$. Diketahui bahwa sig.(2-tailed) sebesar $0.000<0,05$ maka dapat disimpulkan bahwa terdapat perbedaan atau pengaruh yang nyata pada variable pre test dan post test, demikian pada penelitian ini menunjukan bahwa ada pengaruh yang signifikan mengenai terapi reminiscence terhadap harapan hidup lansia di panti werdha welas asih Singaparna Kabupaten Tasikmalaya.

\section{PEMBAHASAN}

Hasil penelitian didapatkan sebagian besar responden termasuk kategori harapan hidup rendah dengan frekuensi (47\%), Maka dapat disimpulkan sebagian besar lansia mengalami harapan hidup rendah sebelum diberikan intervensi.

Lansia yang berada di Panti Werdha Welas Asih ini cenderung mengalami banyak perubahan baik secara fisik, psikologis,sosial, dan spritual. Terutama pada perubahan psikologis dikarenakan lansia jauh dari keluarga yang menyebabkan lansia sering melamun dan hanya berdiam diri dilingkungan panti yang tidak bisa keluar. Hal ini lah yang menyebabkan harapan hidup lansia menjadi rendah yang menyebabkan sumber akumulasi stress. Kemudian dengan diberikannya terapi reminiscence ini diharapkan harapan hidup lansia menjadi lebih meningkat. dapat melakukan kegiatan mengenang bersama teman-teman lansia lainnya
Hasil penelitian harapan hidup lansia setelah diberikan intervensi didapatkan sebagian besar pada kategori harapan hidup hidup sedang (87\%), maka dapat disimpulkan sebagian besar lansia mengalami harapan hidup sedang setelah diberikan intervensi.

Hal ini menujukan bahwa ada perbedaan pada pre test dan post test yang dimana ada pengaruh yang nyata terkait pengaruh terapi reminiscence terhadap harapan hidup lansia di panti werdha welas asih Singaparna Kabupaten Tasikmalaya dengan dibuktikan adanya peningkatan pada frekuensi post test yang awalnya lansia mengalami harapan hidup rendah setelah diberikan intervensi terapi reminiscence harapan hidupnya meningkat dan termasuk kedalam kategori harapan hidup sedang.

Berdasarkan hal itu lansia yang telah diberikan intervensi Terapi Reminiscence ini bnayak mengalami perubahan, baik itu dalam dirinya sendiri maupun dalam berkelompok. Seperti hal nya ada interaksi antara satu sama lain, berbagi cerita dan berbagi moment indah di masa lalu yang membuat lansia menjadi lebih responsive di kegiatan hari harinya.

Berdasarkan hasil pengamatan selama penelitian, terapi reminiscence cocok untuk diterapkan pada lansia karena terapi ini merupakan terapi yang mudah untuk dilakukan. Terapi ini dapat dilakukan baik secara terstruktur maupun tidak terstruktur. Dalam lingkungan sehari-hari lansia Pertahanan hubungan peran keluarga sebagai sesuatu yang penting 
bagi tingkat harapan dan coping begitu sebaliknya kurangnya ikatan sosial diatribusikan sebagai hasil kesehatan yang lebih buruk seperti peningkatan morbidity dan kematian awal. Individu mengekspresikan perasaan tidak berdaya ketika mereka tidak mampu berkomunikasi dengan orang lain.

Begitu pula dengan penyebab lansia yang berada di panti werdha welas asih Singaparna Kabupaten Tasikmalaya mengalami harapan hidup rendah disebabkan oleh beberapa penyebab seperti tidak memiliki motivasi hidup, sering menyendiri dan melamun, serta tidak optimal dalam berproses atau berinteraksi dengan yang lainnya. Akan tetapi hal itu juga dapat diatasi dengan adanya keyakinan atau kepercayaan lansia yang dapat mendorong lansia untuk kembali atau memperoleh suatu harapan untuk meningkatkan kemampuan serta menyiapkan diri di masa usia lanjutnya.

\section{SIMPULAN}

Harapan hidup lansia yang berada di panti werdha welas asih Singaparna Kabupaten Tasikmalaya sebelum diberikan intervensi (pre test) ada pada kategori harapan hidup rendah yaitu (47\%).

Harapan hidup lansia yang berada di panti werdha welas asih Singaparna Kabupaten Tasikmalaya sesudah diberikan intervensi (post test) ada pada kategori harapan hidup sedang yaitu (87\%).

Ada perbedaan yang signifikan antara hasil pre test dan post test yang menunjukan adanya pengaruh terapi reminiscence terhadap harapan hidup lansia di panti werdha welas asih Singaparna Kabupaten Tasikmalaya Tahun 2021 dengan nilai sig 0,000.

\section{SARAN}

Pembahasan terkait pengaruh terapi reminiscence terhadap harapan hidup lansia dijadikan tambahan kepustakaan di bidang ilmu keperawatan, agar dapat memperluas pengetahuan mahasiswa dalam mempelajarinya.

\section{DAFTAR PUSTAKA}

False, D., True, D., \& Scale, T. F. (2020). Adult Hope Scale. Definitions.https://doi.org/10.3238 $8 / 5 \mathrm{k} 38 \mathrm{~g} 7$.

Gea, R. S. (2019). Pengaruh Terapi Reminiscence Terhadap Stres Pada Lansia di Gereja ST. Fransiskus Asisi Padang Buln Medan 2019.

Julianto. (2018). Pengaruh Terapi Reminiscene Terhadap Skor Depresi Pada Lanjut Usia Di Panti Jompo Graha Werdha Marie Joseph Pontianak Utara dan Panti Jompo Graha Kasih Bapa Kabupaten Kubu Raya. Undergraduate Thesis, 58(12), 7250-7257.

Pastiwi, F., Nurfianti, A., \& Hastuti, M. F. (2017). PENGARUH TERAPI KELOMPOK POSITIVE REMINISCENCE Lansia merupakan suatu proses alami yang terjadi dan tidak dapat dihindari manusia sebagai makhluk hidup terbatas oleh suatu peraturan . Dimasa ini seseorang 
mengalami kemunduran fisik , mental dan sosial sec. 3-13.

Pembangunan, U., Veteran, N., \& Kesehatan, F. I. (2020). Standar Operasional Prosedur ( SOP ) Reminiscence Therapy.

Snyder, C. R., Harris, C., Anderson, J. R., Holleran, S. A., Irving, L. M., Sigmon, S. T., et al.(2000). The will and the ways: Development and validation of an individual-differences measure of hope. Journal of Personality and Social Psychology, 60, 570-585.

World Health Organization. (2013). Mental Health And Older Adults, (online).

Indriana, Y. (2010). Tingkat Stres Lansia Di Panti Werdha Pucanggading Semarang. Jurnal Psikologi Undip. Vol. 8, no. 2.

Chen, T.J., Li, H.J., dan Li, J. (2012). The effects of reminiscence therapy on depressive symptoms of Chinese elderly: Study protocol of a randomized controlled trial. BMC Psychiatry, 12, 189.

Syarniah. (2010). Pengaruh Terapi Kelompok Reminiscence Terhadap Depresi Pada Lansia Di Panti Sosial Tresna Werdha Budi Sejahtera Provinsi Kalimantan Selatan. Depok: Fakultas Ilmu Keperawatan Universitas Indonesia.

Hegner, B.R. (2003). Asisten
Keperawatan: Suatu Pendekatan Proses Keperawatan Ed.6. Jakarta: EGC.

Ono, E., Nozawa, T., Ogata, T., Motohashi, M., Higo, N.,Kobayashi, T., Ishikawa, K., Ara, K., Yano, K., Miyake, Y. (2011). Relationship between Social Interaction and Mental Health. SI International 978-14577-1524-2/11/\$26.00 (C2011 IEEE.

Utami, M.S.S. (2012). Terapi Reminiscence dan Snoezelen Untuk Kesehatan Lanjut Usia. Semarang: Universitas Katolik Soegijapranata.

Chiang, K. J. (2009). The Effect of Reminiscence Therapy On Psychological Well-Being, Depression, and Loneliness Among The Institutionalized Aged. International Journal of Geriatric Psychiatry

Sharif, F., Mansouri, A., Jahanbin, I., dan Zare, N. (2010). Effect of Group Reminiscence Therapy on Depression in Older Adult Attending a Day Centre in Shiraz, Southern Islamic Republic of Iran. Eastern Mediterranean Health Journal. Vol.16.No.7.

Pratiwi, M.M.S. dan Pribadi, A.S. (2013). Stres Pada Lansia. Psycho Idea, Tahun 11 No.1, Februari 2013 ISSN 1693-107. 